\title{
The Island on Your Plate: A Comprehensive Approach to Recover the Traditional Food System in Gran Canaria
}

\author{
Adriana Ortiz-Andrellucchi ${ }^{1,2}$, Esther González Padilla ${ }^{1,2}$, Cristina Ruano Rodríguez ${ }^{1,2}$, Ana Luisa Ál- \\ varez Falcón $^{4}$, Lluís Serra-Majem ${ }^{1,2,3,5^{*}}$
}

${ }^{1}$ Research Institute of Biomedical and Health Sciences (IUIBS), Department of Clinical Sciences, University of Las Palmas de Gran Canaria, Las Palmas, Spain

${ }^{2}$ Ciber Obn Physiopathology of Obesity and Nutrition, Institute of Health "Carlos III", Madrid, Spain

${ }^{3}$ International Mediterranean Diet Foundation, London, UK

${ }^{4}$ Hospital Universitario de Gran Canaria Dr. Negrín, Las Palmas, Spain

${ }^{5}$ Nutrition Research Foundation, Barcelona, Spain

*Corresponding author: Lluís Serra-Majem, MD, PhD, Research Institute of Biomedical and Health Sciences, Department of Clinical Sciences, University of Las Palmas de Gran Canaria, Las Palmas, Spain, Tel: (+34) 928453475/ Fax: (+34) 928451416; E-mail: 1luis.serra@ulpgc.es

\begin{abstract}
The island on your plate project highlights the food and culinary richness of Gran Canaria and its importance in health, environment, culture and economy of community. The Food and Agriculture Organization (FAO) goals to Canary Islands become a benchmark for the Macaronesia and the surrounding areas of África, with regard to agriculture and environmental preservation. The island on your plate project is in line with the FAO's proposal, achieving the following objectives: (1) Raise awareness of the gastronomic diversity in the island of Gran Canaria. (2) Proactive intervention on the dietary pattern of the Gran Canaria population by adapting the local habits to a Mediterranean-like Diet. (3) Revitalization of the concept of a traditional local diet. (4) Promote the consumption of local products that meet the standards of freshness, sustainability and diversity. (5) Empowerment and diffusion of the traditional food system of Gran Canaria and the benefits of the Mediterranean Diet. (6) Initiate the dialogue for the creation of a Museum of the Mediterranean Diet in Gran Canaria. This project aims to create greater awareness among the population, about the many possibilities that the territory give us, creating a healthy diet plan to increase the quality of life of the population, respectful with the environment and economy, reverting traditional food system.
\end{abstract}

\section{Contact information}

E-mail: laislaentuplato@ulpgc.es

Facebook: www.facebook.com/laislaentuplato

Web: www.laislaentuplato.org

Received date: September 7, 2016

Accepted date: September 9, 2016

Published date: September 15, 2016

Citation: Serra-Majem, L., et al. The Island on Your Plate: A Comprehensive Approach to Recover the Traditional Food System in Gran Canaria. (2016) J Environ Health Sci 2(4): 1- 5.

DOI: $10.15436 / 2378-6841.16 .1099$

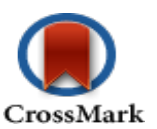

Keywords: Gran Canaria; Environment; Culture; Economy; Gastronomy; Mediterranean diet

\section{Introduction}

The island on your plate project highlights the food and culinary richness of Gran Canaria and its importance in health, environment, culture and economy of community. The Gran Canaria Island is part of the Canary Islands (Spain), which together with the archipelagos of Azores, Cape Verde and Madeira are the Macaronesian region (Figure 1). This region has a unique biogeography, with a rich biodiversity of species.

Copyrights: $(0) 2016$ Serra-Majem, L. This is an Open access article distributed under the terms of Creative Commons Attribution 4.0 International License. 


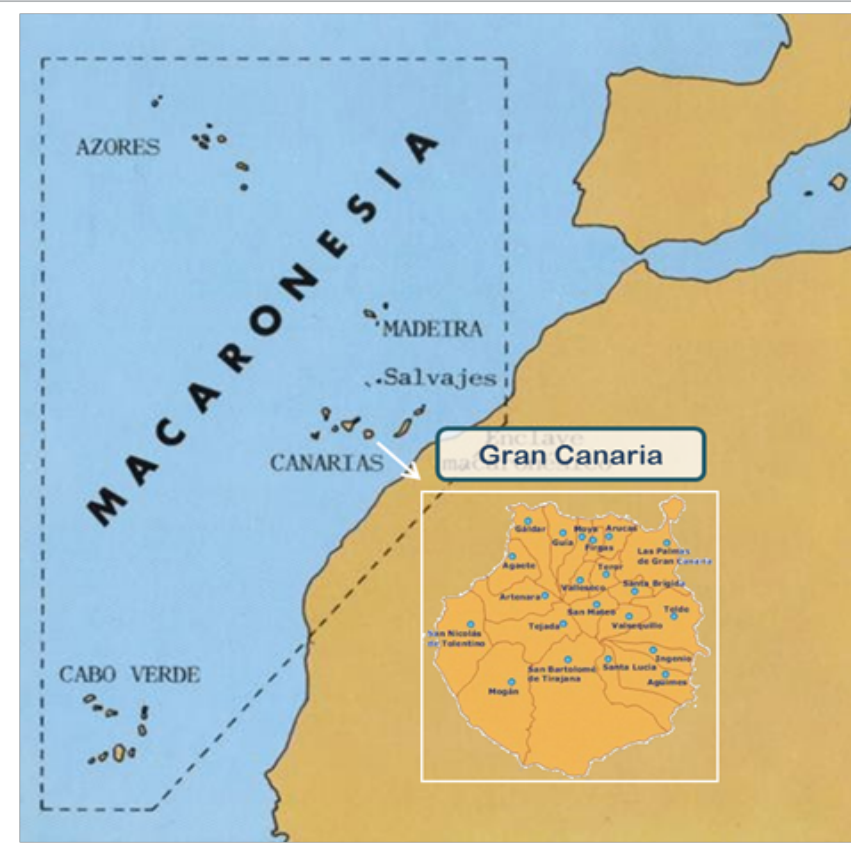

Figure 1: Geographical location of the Gran Canaria Island in the Macaronesian region.

There are very few places in the world like Gran Canaria, where traditionally produced all the ingredients of the Mediterranean diet. This is based on the combination of products and flavors, obtaining maximum performance with minimal resources and a wide variety of dishes and recipes with the same products. The agronomist Louis Albertini (2009) relates the history of the installation and development of Mediterranean cultures, origins until today. On close temperate stretch of land located between northern Europe and tropical Africa, there have been emblematic crops such as wheat, olives and vines, all ingredients of the Mediterranean diet. Albertini introduces us, to the history of the evolution of techniques and acclimatization of plants, to explain how Mediterranean landscapes are, and how they evolve, reflecting that Canarian agriculture and landscapes are Mediterranean. The Mediterranean diet is a cultural, historical, social, territorial and environmental heritage that's been transmitted from generation to generation for centuries, and is intimately linked to the lifestyles of the Mediterranean peoples throughout their history. (Serra-Majem and Medina, 2015). In this transmission of knowledge of gastronomic culture from generation to generation, the mothers were a key role, and now, the gastronomy and tourism sector should target their services towards a Quality Canarian Cuisine based in local and Mediterranean foods. Promoting use of local traditional food biodiversity is an essential driver of food system sustainability for peoples, and contributes to global consciousness for protecting food biodiversity and food system sustainability more broadly (Kuhnlein, 2015). The Mediterranean dietary pattern is presented not only as a cultural model but also as a healthy and environmentally friendly model (Serra-Majem et al., 2011; Germani et al., 2014) (Figure 2).

\section{Mediterranean Diet $\mathbf{~}$ Sustainable Diet}

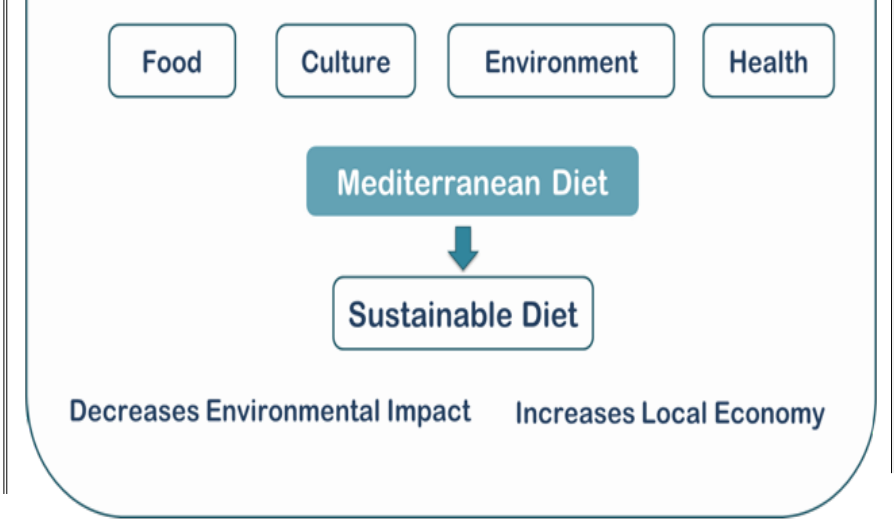

Figure 2: The Mediterranean diet as an example of suitable diets.

The Food and Agriculture Organization (FAO, 2016a) goals to Canary Islands become a benchmark for the Macaronesia and the surrounding areas of Africa, with regard to agriculture and environmental preservation. The island on your plate project is in line with the FAO's proposal, achieving the following objectives:

(1) Raise awareness of the gastronomic diversity in the island of Gran Canaria and the importance of Health, Environment, Culture and Economy.

(2) Proactive intervention on the dietary pattern of the Gran Canaria population by adapting the local habits to a Mediterranean-like Diet.

(3) Revitalization of the concept of a traditional local diet.

(4) Promote the consumption of local products that meet the standards of freshness, sustainability and diversity.

(5) Empowerment and diffusion of the traditional food system of Gran Canaria and the benefits of the Mediterranean Diet.

(6) Initiate the dialogue for the creation of a Museum of the Mediterranean Diet in Gran Canaria.

A change, to return to the roots and to recover lost habits and customs. A change, a few steps backwards in the way to food globalization, to recover the Mediterranean Diet, indisputable emblem of public health and cultural identity.

\section{The Book: "The Island on your Plate"}

This book shows by topic, different groups of local foods that are currently produced in Gran Canaria. Treating from their origin to their connection with traditions, without forgetting how and when we can find them, their characteristics, their nutritional value and explaining how to include them in the diet, so that we have all the advantages in health, enjoyment and taste.

This document aims facilitate a change in eating habits in the Canarian population, towards follow one based on the use of local and seasonal products, which is in essence one of the pillars of the Mediterranean diet, that not only ensures the variability of food consumed, also promotes environmental sustainability, preserving its nutritional characteristics and taste of 
foods. This book highlights the wide range of products available in Gran Canaria, mainly due to two factors: the beautiful and unique biodiversity that presents the island and the cultural miscegenation that it have been exposed to throughout history as a point of departure and return between continents

Figure 3 shows the variety food groups integrated in the local and traditional food production in Gran Canaria, addressing the basic elements of the Mediterranean Diet. This book also collects details related to the production and elaboration process, popular culture and an assortment of traditional recipes. Here the food and food groups are as follows:

(1) The Gofio: It is one of the most representative elements of the Canarian diet; employing the word "gofio" since the time of the aborigines of Gran Canaria. Gofio is the product resulting from grinding any grain toasted previously; the "gofio" of corn and wheat are the most common.

(2) Bread: The bread is included in the group of cereals and carbohydrate content does essential and basic in the Mediterranean diet. Gran Canaria has variety of breads, such egg corn or potato bread.

(3) Potatoes: The Canary region has great tradition in the potato cultivation. In fact, it is responsible for introducing this food in Europe. We can find old potatoes from America and that remain unhybridized and varieties that emerged from the adaptation a new environment in Europe.

(4) Legumes: It was introduced in the Canary region by the Aborigines, who grew mainly lentils, peas or beans, which are stored in silos. In addition to being a nutritious food, the legumes preserved the fertile farmland. Currently the cultivation of legumes in GranCanaria is limited to market garden for local consumption. However, continue to occupy a prominent role in the Canarian cuisine, often used in combination with meat and potatoes, or as strong dishes for cooler days. Some of these canaries dishes made with legumes are: "RopaVieja", "RanchoCanario", "Arvejas" and "Garbanzas".

(5) Olive \& olive oil: The pillar of the Mediterranean diet. Gran Canaria island stands out as the most area of land dedicated to the olive tree cultivation in the Canary Islands. It located mainly, in the east of the island between 300 and $950 \mathrm{~m}$ above of sea level. However, we can also find areas dedicated to this crop in the South of Tenerife and Fuerteventura.

(6) Plátano: The "plátano canario" is an exclusive product of the Canary Islands, it is different from banana of America, which is cut with less maturity level (3 months), while the "plátanocanario" mature 6 months at the plant, this gives a different nutritional composition. Currently in Gran Canariathe cultivation focusesprincipally on the north and northeastof the island.

(7) Mango: It was introduced to the islands in the late eighteenth century brought from the Philippines, later inthe nineteenth century came over from Cuba and Venezuela.

(8) Papaya: This plant is grown in the islands for 200 years, associated with other crops. Currently its cultivation has expanded. (9) Tomatoes: It has marked the development of areas of the southeast and northeast of Gran Canaria Island. At present, is the leading export crop of the island.

(10) Cheese: It is a very important product of the Canarian tradition. Currently, in the Canary Islands exists the biggest production and consumption of goat cheeses in Spain.

(11) Canarian Black Pork: The ancient Canarian settlers made it very large source of resources, using their meat and butter, their skin for clothes and bones for tools and ornaments. Rabbit is also a typical dish: "conejosalmorejo".

(12) Chorizo Canario: Canary essential food supply which often appear in both the canary parties and simple household snacks.

(13) Fish \& Fishing: Excellent seabeds give the islands a splendid and rich marine life, and therefore, a tasty cuisine in products from the sea.

(14) Nuts: There are important plantations of almonds, walnuts and chestnuts on the island

(15) Mojo Canario: It is a typical sauce in the Canary Islands that accompanies lots of Canarian dishes in order to enrich and enhance their flavors.

(16) Coffee: Agaete, municipality northwest of Gran Canaria, currently hosts more than 60 farmers engaged in the cultivation of Arabica coffee plants

(17) Honey, sugar \& desserts: There are old sugar mills on the island. Gran Canaria's honey is produced primarily by the black bee from the nectar of flowers and matures stored in honeycombs. Sugar is an example of lack of sustainability and a source of forest erosion, because the wood was used as material for the installation of the sugar mills.

(18) Wines \& Ron: The $10 \%$ of useful agricultural land in the archipelago is occupied by vineyards.

(19) Water: It has always been a scarce resource in the Canary Islands. Dams or wells have been created to obtain it, especially from underground aquifers.

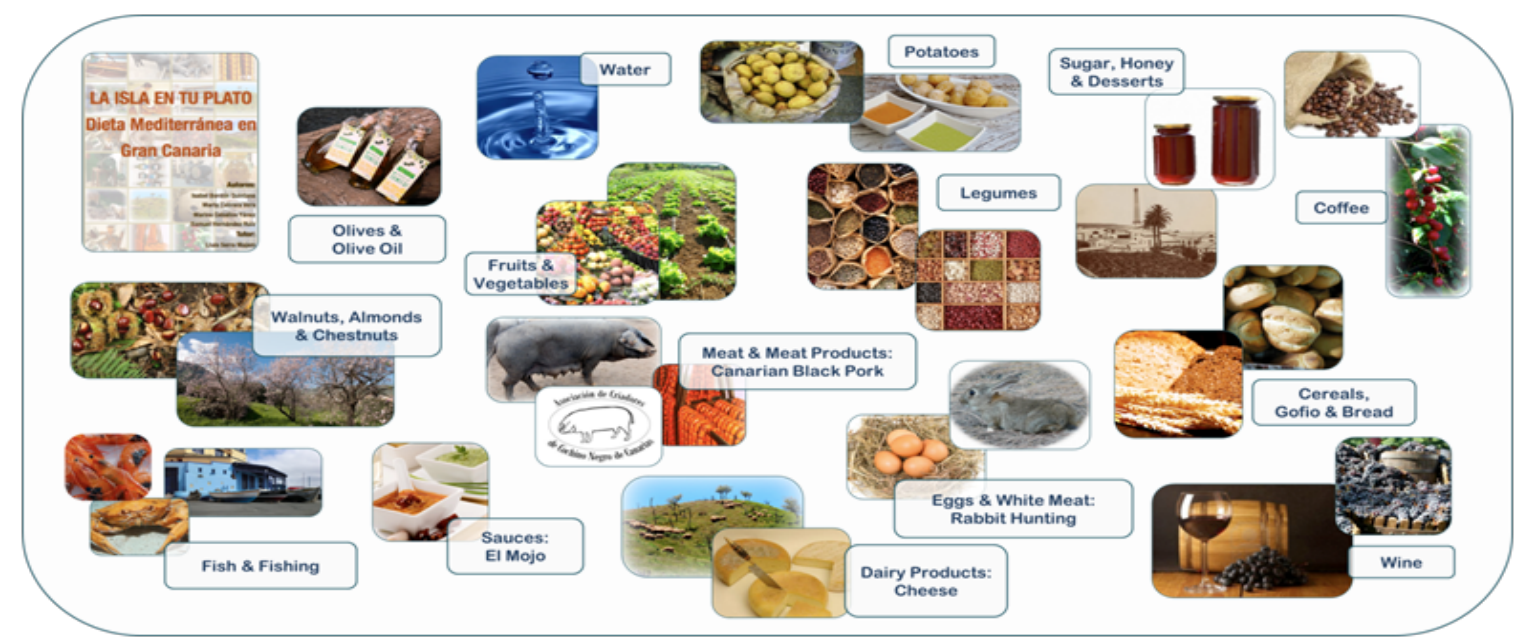

Figure 3: Food groups integrated in the local and traditional food production in Gran Canaria. 


\section{Mediterranean Diet Museum: an educational space}

This space provides the means to reach the public and transmitting the essence of a balanced diet and fresh products of Gran Canaria. This museum aims to guide tourists and the local population, through the variety of products that are part of the Canarian food and thereby reassess the Canarian gastronomy and identity. This is a Cultural and Educational Space for Gastronomy, Agriculture, Farming and Fishing, where a special focus is made on the following strategic points: (1) Tourism: Education and information for tourists. High quality tourism, engaged with local culture and landscape; (2) Local: Promote the local traditions regarding food and culture in Gran Canarian kitchens, (3) Professionals: Provide information for individuals and institutions related to Food, Community Nutrition, Sustainability and Public Health.

\section{The 2030 Agenda for Sustainable Development}

United Nations (2015) in the document "Transforming our world: the 2030 Agenda for Sustainable Development", determined to protect the planet from degradation, including through sustainable consumption and production, sustainably managing its natural resources and taking urgent action on climate change, so that it can support the needs of the present and future generations. The Goal 12 of this agenda aims to ensure sustainable consumption and production patterns. Sustainable consumption and production is about promoting resource and energy efficiency and sustainable infrastructure. Sustainable consumption and production aims at "doing more and better with less," increasing net welfare gains from economic activities by reducing resource use, degradation and pollution along the whole lifecycle, while increasing quality of life. The 17 Sustainable Development Goals are integrated and indivisible and balance the three dimensions of sustainable development: the economic, social and environmental.

Diets link environmental and human health. The implementation of dietary solutions to the tightly linked diet-environment-health trilemma is a global challenge, and opportunity, of great environmental and public health importance (Belahsen, 2014; Tilman and Clark, 2014; Vanham and Bidoglio, 2014). Urbanization and the transformation of agriculture, food systems and rural spaces present challenges and opportunities for inclusive growth, poverty eradication, economic, environmental and social sustainability, and food security and nutrition (FAO, 2016b; International Urban Food Network, 2016). The "Decalogue for sustainable food and nutrition in the community: Gran Canaria Declaration 2016" aims to improve food sustainability across the globe (Serra-Majem,L. et al., 2016). This guide is a pioneer in the field, with worldwide significance and developed from conclusions drawn from the Community Nutrition and Sustainability Expert Meeting held at the beginning of April at the Gran Canarian municipalities of Santa Brígida and Vega de San Mateo. Public Health, Nutrition, Consumer, Social, Marine and Environmental Sciences and Tourism are important topics that have been highlighted in this Decalogue, whose full implementation promote the development of sustainable consumption and production patterns.

All these reasons, supports the development of this project that aims to create greater awareness among the population, about the many possibilities that the territory give us, creating a healthy diet plan to increase the quality of life of the population, respectful with the environment and economy, reverting traditional food system.

Acknowledgments: Special thanks to the following partners: Research Institute of Biomedical and Health Sciences (IUIBS); Spanish Academy of Nutrition and Food Sciences (AEN); Nutrition Research Foundation (FIN); Spanish Society of Community Nutrition (SENC); International Foundation of Mediterranean Diet (IFMeD). A particular acknowledgement is made for the support provided bythe following local organizations related to food, gastronomy and tourism: Cheese House; Asoflor Association; Wine Village of Santa Brígida; Pastry Store "Nublo", Tejeda; Gofio "BuenLugar", Firgas; Sausage Factory "The Nuts", Teror; Bakery "El Puente", Ingenio; D.O.P. Wines of Gran Canaria and Agroagaete. The collaborative support provided by Isabel Bordón (MD), Marta Cabrera (MD), Marina Ceballos (MD), Samuel Hernández (MD), Antonio Martell, Francisco SocorroSaavedra, Fernando de laFuente, JoséFrancisco Mendoza, ManoloMartel, Luis Sánchez López, Luis Calvo and José A. Gonzálezis also acknowledged. 


\section{Reference}

1. Afonso-Carillo, J. Agricultura en Canarias conciliando tradición y ciencia. (2012) Instituto de Estudios Hispánicos de Canarias 174.

2. Albertini, L. Agricultures méditerranéennes: agronomie et paysages des origines à nos jours. (2009) Actes Sud, France 432.

3. Asociación Asoflor. Denominación de Origen Protegida Queso de Flor de Guía, Queso de Media Flor de Guía y Queso de Guía. (2012) Ministerio de Agricultura, Alimentación y Medio Ambiente.

4. Asociación de Criadores de Cochino Negro Canario. (2016) (Accessed 5 September 2016).

5. Bas, C. et al. La pesca en canarias y áreas de influencia. $1^{\mathrm{a}}$ ed. Ediciones del Cabildo Insular de Gran Canaria, Las Palmas de Gran Canarias, Spain, (1995).

6. Belahsen, R. Nutrition transition and food sustainability. (2014) Proc Nutr Soc 73(3): 385-388.

7. Consejo Insular de Aguas de Gran Canaria. (Accessed 5 September 2016).

8. FAO. La FAO quiere que Canarias sea referente para la Macaronesia en agricultura ecológica. (2016a)

9. FAO. Global Forum on Food Security and Nutrition. (Accessed 5 September 2016)

10. Federación Insular de Asociaciones del Sector Vitivinícola de Gran Canaria (VINIGRAN) (2012) Denominación de Origen Gran Canaria Canarias: Casa del Vino.

11. Felo Botello. Gastronomía y paisaje de Gran Canaria. (2007) $1^{\mathrm{a}} \mathrm{ed}$ Gastrovida; Las Palmas de Gran Canaria.

12. German, A., Vitiello, V., Giusti, A.M., et al. Environmental and economic sustainability of the Mediterranean Diet. (2014) Int J Food Sci Nutr 65(8):1008-1012.

13. Gobierno de Canarias. Manual del consumidor de vinos de Canarias. Canarias: Comunidad Autónoma de Canarias. (2010) Instituto Canario de Calidad Agroalimentaria.
14. Ilustre Ayuntamiento de la Villa de Agüimes. (2013) Elaboración del aceite de oliva virgen extra Caserío de Temisas.

15. International Urban Food Network (IUFN). Guide Methodologique - Construire son Projet Alimentaire Territorial (Accessed 5 September 2016).

16. Kuhnlein, H. Food system sustainability for health and well-being of Indigenous Peoples. (2015) Public Health Nutr 18(13): 2415-2424.

17. Quintana Navarro, F., Márquez Quevedo, J. Una mirada crítica a la agricultura canaria: la obra periodística de José Mauricio Rodríguez, 1959-1989. (1996) $1^{\text {a }}$ ed. Ediciones del Cabildo Insular de Gran Canaria, Las Palmas de Gran Canaria.

18. Rebollo, M. El tomate en Gran Canaria. (2013) $1^{a}$ ed. Anroart Ediciones, S.L; España

19. Serra-Majem, L et al. Foreword: Mediterranean diet and climatic change. (2011) Public Health Nutr 14(12A): 2271-2273.

20. Serra-Majem, L., Medina, X. The Mediterranean Diet as an Intangible and Sustainable Food Culture. (2015) In: Preedy, V. and Watson, R. (Eds), The Mediterranean Diet. An Evidence-Based Approach. London: Elsevier, pp. 37-46.

21. Serra-Majem, L. et al. Decalogue for sustainable food and nutrition in the community: Gran Canaria Declaration. (2016) J Environ Health Sci (in press).

22. Suárez Moreno, F. Apuntes sobre la historia del ron de caña en Canarias y Madeira. (2011) El alambique de La Aldea (Accessed 6 September 2016).

23. Tilman, D., Clark, M. Global diets link environmental sustainability and human health. (2014) Nature 515(7528): 518-522

24. UN. Sustainable Development Goals. (2015) (Accessed 5 September 2016).

25. Vanham, D., Bidoglio, G. The water footprint of Milan. (2014) Water Sci Technol 69(4): 789-795.
Ommega Online Publishers

Journal Title: Journal of Environment and Health Science (JEHS)

Journal Short Name: J Environ Health Sci
Journal ISSN: 2378-6841

E-mail: environmentalscience@ommegaonline.org

Website: www.ommegaonline.org 